Article

\title{
Watching over or Working with? Understanding Social Work Innovation in Response to Extra-Familial Harm
}

\author{
Lauren Elizabeth Wroe * and Jenny Lloyd (1) \\ Institute of Applied Social Research, University of Bedfordshire, Room F303, Park Square, Luton LU1 3JU, UK; \\ jenny.lloyd@beds.ac.uk \\ * Correspondence: lauren.wroe@beds.ac.uk
}

Received: 27 February 2020; Accepted: 26 March 2020; Published: 1 April 2020

check for updates

\begin{abstract}
This paper critically reflects on the role of surveillance and trusted relationships in social work in England and Wales. It explores the characteristics of relationships of trust and relationships of surveillance and asks how these approaches apply to emerging policy and practices responses to extra-familial forms of harm (EFH). Five bodies of research that explore safeguarding responses across a range of public bodies are drawn on to present an analytical framework that explores elements of safeguarding responses, constituting relationships of trust or relationships of surveillance and control. This analytic framework is applied to two case studies, each of which detail a recent practice innovation in response to EFH studied by the authors, as part of a larger body of work under the Contextual Safeguarding programme. The application of this framework signals a number of critical issues related to the focus/rationale, methods and impact of interventions into EFH that should be considered in future work to address EFH, to ensure young people's rights to privacy and participation are upheld.
\end{abstract}

Keywords: care; child protection; contextual safeguarding; control; extra-familial harm; surveillance

\section{Introduction}

Since the first social services departments in England and Wales in 1971 were established, social work has seen a seismic shift in its scope and remit, placing increased demands on social workers and, arguably, increased surveillance on a broader population of children and families (Parton 2019). The increased bureaucratization of social work appears alongside the encroachment of neoliberal values into social welfare systems (Eubanks 2018), where families become problems to be managed. One feature of this bureaucratization is the use of surveillance (through data collection, monitoring and risk assessment) to assess, prevent and monitor social harms, and the subjects of social welfare. This has been subject to significant academic (Penna 2005; Edwards 2016; White and Wastell 2017) and sector debate (Shabde and Craft 1999; Mellon 2017). Yet, alongside what some (McKendrick and Finch 2017) term the 'securitization' of social welfare, and social work specifically, the importance of relationships and relational ways of working has remained intact (Bryan et al. 2016; Care Crisis Review 2018).

Working with families has been positioned as dichotomous to 'watching over' (surveillance from the French: 'sur' —'over' and 'veiller' —watch), highlighting contradictions in surveillance and relationship centred social work (Parton 2011). A body of literature details the detrimental impact of over-surveillance on relationships between young people and statutory bodies (Fine et al. 2003; Williams 2018). Relational ways of working and the participation of young people and families in social work have been championed as promoting not only effective social work practice but the rights of children and families that should underpin any such intervention (Cossar et al. 2016). 
Within ostensibly incompatible paradigms, social work is tasked with responding to ever-changing forms of harm. While child protection in England and Wales has historically focused on the risks that children face within their families, there is increasing awareness of harm happening outside the home (Firmin 2017; Department for Education 2018b). Abuse such as child sexual exploitation (CSE), serious youth violence and child criminal exploitation (CCE) are often forms of extra-familial harm (EFH) occurring in social settings beyond the home. As such, policy and practice across England and Wales are placing greater requirements on multi-agency partnerships to respond to contexts where harm occurs, most recently through the inclusion of Contextual Safeguarding in safeguarding guidance (Llywodraeth Cymru 2019; Firmin 2017; Department for Education 2018b). Working Together (Department for Education 2018b) notes that social workers should "understand the level of need and risk in, or faced by, a family from the child's perspective" (p. 28) and "interventions should focus on addressing wider environmental factors" (p. 22). The recognition of EFH as a form of child abuse has been welcomed by many working within child protection to address the system challenges practitioners face when responding to harm outside the home (ADCS 2017; Department for Education 2018a).

The broadening of child protection frameworks to the harm faced by, as well as within, families, places new demand on children's services: how to respond effectively to EFH within child protection legislative frameworks, with questions around thresholds, partnerships and interventions currently unanswered. These are not simply technical or operational questions; the expansion of the child protection lens to new arenas of private and public life poses ethical questions around which social work values, theory and practices will drive innovation in the area of EFH. If current child protection practice is experienced as adversarial and punitive (Morris 2012) and young people report distrust and isolation in response to surveillance in their families, schools and communities (Fine et al. 2003; Williams 2018), how can new practice responses to EFH learn from decades of debates and scholarship in social work to inform effective and ethical interventions? This article explores these questions in further detail, drawing upon two current practice responses to EFH that use a Contextual Safeguarding Framework, to evaluate the extent to which the interventions represent an extension of welfare-driven and care-led responses to child abuse, or further the encroachment of punitive forms of state surveillance into the lives of young people and their families.

\section{Interventions into Extra Familial Harm}

Children subject to child protection interventions have steadily increased in England and Wales since the 1990s (Department for Education 2019). In 2017, the number of children in care was its highest since the Children Act 1989 (Care Crisis Review 2018). James Munby named this a 'crisis' in child welfare and a 2018 Family Rights Group report, aimed at addressing the crisis, concluded that cultures of blame "led to an environment that is increasingly mistrusting and risk averse and prompts individuals to seek refuge in procedural processes" (Care Crisis Review 2018, p. 5). Whereas child protection interventions have traditionally focused on harm in the family, increasing focus on EFH arguably broadens the child protection lens. In 2019, the Children's Commissioner reported increasing numbers of young people aged 12 or more entering care for the first time, often as a result of EFH (Stability Index 2019).

Yet, growing awareness and high-profile cases of EFH, such as CSE (Jay 2014), have raised questions about the efficacy of child protection services to respond to the harm children face externally to their families (Munro 2011; Lloyd and Firmin 2019). In response, a number of practice and policy frameworks are emerging. Contextual Safeguarding is one approach, seeking to expand the reach of child protection systems into a range of social contexts beyond families such as peer groups, schools and neighbourhoods (Firmin 2017). Despite the inclusion of Contextual Safeguarding in statutory guidance, there are few practical suggestions as to how to do so. As such, agencies are developing their own practice frameworks, either through specific reference to Contextual Safeguarding or emphasis on community-based or location-specific practices. For example, through the use of peer group mapping 
(to identify children's peer relationships) and safety mapping (by exploring young people's experiences of safety and risk in their neighbourhoods) (ALDCS 2018).

Responses to EFH require child protection systems to respond to forms of harm that had previously been criminalized or understood as outside the remit of child safeguarding. These include forms of youth exploitation and violence; from CSE, to serious youth violence and more recently the exploitation of children to distribute drugs via 'county lines'. Whilst increased sector attention to these forms of harm (and recognition they are forms of child abuse) are welcomed, responses to EFH are ubiquitously accompanied by increases in surveillance practices and technologies. From the monitoring of young people's social media accounts by schools and social workers (Shade and Singh 2016; Montgomery 2015), to mandatory reporting by civic institutions of children at risk of 'radicalization' (McKendrick and Finch 2017; Stanley et al. 2018), or serious youth violence (Community Practitioner 2019), the use of multi-agency risk panels and databases to record, share and monitor 'at risk' young people (Williams and Clarke 2016), the use of child Covert Human Intelligence Sources to investigate child exploitation (Twite 2018) and the increased use in managed moves and secure accommodation (Stability Index 2019). Whilst these interventions are justified by a need to safeguard children and young people, they present significant challenges to rights-based approaches grounded in participatory and relational ways of working. Wrennall (2010) describes these kinds of child protection interventions as a 'Trojan horse', via which extensive surveillance practices are justified with often competing or contradictory policing or other social, political or economic goals.

\section{Extra-Familial Harm and Surveillance Approaches}

The recognition of EFH as child abuse impacts both the scope and remit of child protection and the subsequent interventions. A major outcome of the Care Crisis Review, which sought to address the rising number of young people entering care, was recognition of professionals' desire to 'work with' rather than 'do to' families, and similarly families and young people expressed a 'strong desire' (Care Crisis Review 2018, p. 5) to work with services to improve systems for protecting children. Partnership with children and families is a founding principle of the Children Act 1989, and is enshrined in international rights treaties (UNCRC 1989, Article 12) and supported by a vast academic and practice research (see van Bijleveld et al. 2013; Cossar et al. 2016). As the Care Crisis Review summarized:

There was consensus that relationship building has been and is at the heart of good practice. The challenge for all of us is how to create the conditions within children's social care and family justice that allow good relationships to flourish everywhere, within and between agencies, within families, and between families and practitioners. (Care Crisis Review 2018, p. 4)

Yet, for some, relational forms of practice are under threat from institutions tasked with protecting children and young people. Hingley-Jones and Ruch (2016) draw on Parton's (2000) conceptualization of the social worker as inhabiting the 'social' space between the individual and the state. They position relational social work, where the social worker positions themself alongside families to find "solutions to problems in living" (Hingley-Jones and Ruch 2016, p. 240), as increasingly restricted. They ask, what role can the social worker play in mediating between the individual and a state that does not listen to the needs of young people and families, instead subjecting them to discipline and management approaches? Such approaches are documented as increasingly targeting children and families through relationships of control and surveillance (Edwards 2016; White and Wastell 2017).

The negative impact of experiences of surveillance on trusted relationships with young people is well documented, particularly where this intersects with class and race. A 2003 study exploring the surveillance experiences of young people in urban public places in New York concluded: 
urban youth, overall, express a strong sense of betrayal by adults and report feeling mistrusted by adults, with young men of color most likely to report these perceptions. (Fine et al. 2003, p. 142)

Fine et al. (2003) propose that youth perceptions of authority surveillance undermine trust and may have "adverse developmental and also democratic consequences of society as a whole" (Fine et al. 2003, p. 143). Similarly, O'Neill and Loftus (2013) detail how intensive information gathering, within unreflexive and loose information sharing arrangements, disproportionately impacts already marginalized individuals, families and communities. Recent research into the monitoring of young people on the London 'Gangs Matrix', as a means of addressing serious youth violence and 'gang' association, similarly demonstrates the lasting impact of surveillance activity. An Amnesty (2018) report into the Gangs Matrix highlighted significant and lasting impacts to education and employment opportunities for young people.

\section{Analytical Framework}

The impacts of surveillance as a form of 'watching over' rather than 'working with' are further amplified when EFH and adolescence are considered. In light of this need, and the changing landscape of child protection in response to EFH, we develop an analytical framework to explore how contemporary approaches to EFH fare in way of these debates. Drawing upon five bodies of research, individually exploring safeguarding responses across a range of public bodies, we present an analytical framework that explores elements of safeguarding responses, constituting relationships of trust (Bryan et al. 2016) or relationships of surveillance and control (Fernandez and Huey 2009). A focused literature review was conducted. Academic and grey literature was searched using focused search terms. English language returns were reviewed in the period 2000-2020 to capture debates emerging in the last two decades on control/surveillance and trusted relationships in social care and to capture the period that the issue of child exploitation and EFH entered child protection practice and policy discourse. Five papers were selected that effectively distilled or exemplified themes emerging in the broader search. The five studies underpinning this framework consider the role of statutory agencies in the lives of young people and families and have been selected on the basis that they tackle the dynamics of trust and surveillance in such interventions. O'Neill and Loftus (2013) (article one) detail how social policy focused on crime control contributes to accelerating surveillance processes, which target 'problematic' individuals through detailed data sharing across public sector bodies. Focusing on the policing of adolescents, Fine et al. (2003) (article two) consider the process of alienation young people feel through increasingly punitive police practices. For Wrennall (2010) (article three), the rhetoric of child protection is seen to be a 'Trojan horse', whereby the seemingly innocuous aim of protecting children justifies and normalizes the encroachment of expansive and powerful legislation and techniques which disguise the surveillance of young people for the economic, political and commercial interests of the state and other parties. The Care Crisis Review (2018) (article four) includes a rapid academic review resulting in 20 recommendations for change, based on a consensus that relationship building is 'at the heart of good practice', despite current cultures of blame, anxiety, mistrust and distance between professionals and families. Similarly, Hingley-Jones and Ruch (2016) (article five) locate professional anxiety in the context of neoliberalism and austerity as a barrier to relational ways of working. Using a psychoanalytical and structural framework, the authors argue 'life begins with relationships' but that financially austere socio-political climates create a 'relational austerity' (2016, p. 237), where practice is authoritative and combative rather than assertive and compassionate.

\section{Creating an Analytic Framework}

Drawing on these studies, we present an analytical framework which explores the components of systems constituting welfare and participatory approaches based on relationships of trust with young people, or systems and interventions where relationships between services and young people are characterized by surveillance and monitoring. 
Table 1 distils the learning from the articles detailed above across three areas:

- Focus/rationale: Who or what is the focus of the intervention and what is the legal/moral justification?

- Method: How does the system or intervention pursue its aim and through which methods?

- Impact: What is the impact on those subject to interventions?

Table 1. Key components of five studies (numbers indicate article).

\begin{tabular}{|c|c|c|}
\hline & Relationships of Trust & Relationships of Surveillance \\
\hline Focus/rationale & 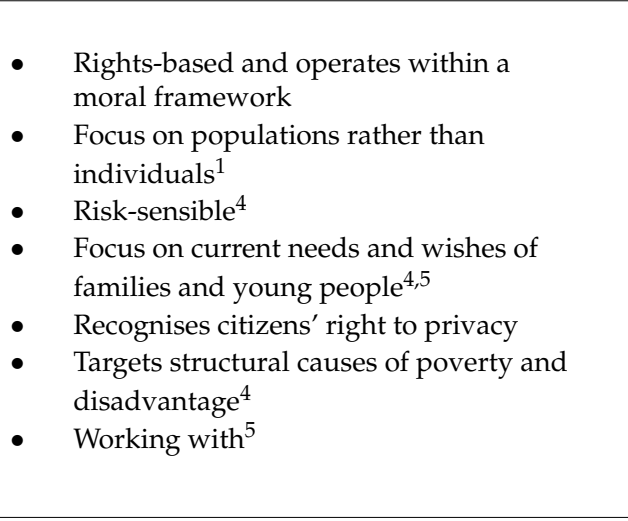 & $\begin{array}{l}\text { - Legal basis is the prevention of antisocial } \\
\text { behaviour or crime and disorder }{ }^{1} \text { bypassing } \\
\text { civil liberties, data protection and human } \\
\text { rights legislation }\end{array}$ \\
\hline Method & $\begin{array}{l}\text { - Intelligent use of data shared for intended } \\
\text { purposes with informed consent is } \\
\text { proportional and considered } \\
\text { - } \quad \text { Formal and transparent partnership } \\
\text { arrangements and secure sharing, with } \\
\text { systems in place to hold individuals } \\
\text { to account } \\
\text {-Felt thoughtfulness'-feelings matter. } \\
\text { Principles of humanity, kindness and } \\
\text { warmth are emphasised } \\
\text { - Focus on capabilities and prioritises } \\
\text { resources that support families, drawing on } \\
\text { relationships and restorative practice } \\
\text { Relationships with families and } \\
\text { communities and meaningful contact is at } \\
\text { the heart of practice,4 } \\
\text { Practice is confident, strengths-based, } \\
\text { authoritative and has humility. Systems are } \\
\text { open to uncertainty, complexity, irrationality } \\
\text { and subjectivity. The limits and impact of } \\
\text { interventions are recognised }\end{array}$ & 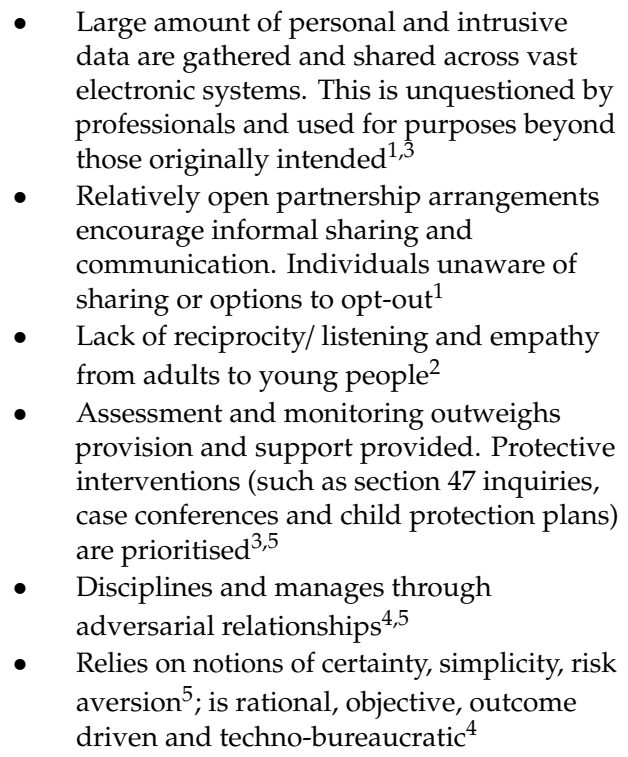 \\
\hline Impact & $\begin{array}{l}\text { - Families are supported to understand } \\
\text { professional concerns and draw upon their } \\
\text { own strengths and networks to make safe } \\
\text { plans for their child } 5 \\
\text { - } \quad \text { Results in building, strengthening and } \\
\text { repairing relationships as the key to } \\
\text { long-term stability and security for children } \\
\text { - } \quad \text { Enables young people to develop trust and } \\
\text { build healthy relationships with } \\
\text { professionals }{ }^{5} \\
\text { - } \quad \text { Increases feelings of safety for young people } \\
\text { Eases stress, dispels families' fears and does } \\
\text { not reinforce shame and suffering }{ }^{5} \\
\text { Maintains the 'no order' principle } \\
\text { underpinning the Children Act } 1989 \text {-no } \\
\text { order is made in relation to a child unless } \\
\text { doing so would be better for the child than } \\
\text { making no order at all }{ }^{5}\end{array}$ & $\begin{array}{l}\text { - Individuals provided with welfare rather } \\
\text { than rights through 'coercive paternalism }{ }^{4,3} \\
\text { Negative impact on individuals for housing, } \\
\text { education and employment prospects and } \\
\text { criminalisation'1,3 } \\
\text { - Results in youth alienation and } \\
\text { disengagement from adult society, resulting } \\
\text { in likelihood of seeking help/disclosing }{ }^{2} \\
\text { - Reduces feeling of safety in some places, } \\
\text { moving youth populations from public } \\
\text { space to marginal spaces } \\
\text { - Normalises punitive policing and } \\
\text { sanction-based approaches, such as stop and } \\
\text { search and increasing securitisation }{ }^{2} \\
\text { Financially benefits particular industries } \\
\text { including IT, adoption and foster care } \\
\text { companies and care home companies }{ }^{3}\end{array}$ \\
\hline
\end{tabular}


Table 1 condenses this to capture the core components of each pillar.

Employing this framework, we consider where developments in child protection work, tackling $\mathrm{EFH}$, fall across this relational scale, using findings from the two studies detailed below.

\section{Methodology}

The findings presented here are taken from work undertaken as part of the Contextual Safeguarding programme (Firmin 2017). Since 2011, this programme of work has been concerned with understanding and advancing the efficacy of child protection systems to respond to EFH.

This article presents data from two studies. Both were chosen, and are analysed in tandem, as the interventions they focus on were unique and/or innovative in the way they sought to address a form of $\mathrm{EFH}$. The project under analysis in study 1 innovated by coordinating a regional approach to EFH, bringing together policing, social services and the voluntary sector. The project under analysis in study 2 engaged a contextual assessment and intervention. To ensure anonymity and confidentiality, some details of the projects have been amended.

Ethical approval was granted for all studies from a University of Bedfordshire ethics committee, and in study 1 the participating local authorities ethics board and the Director of Children and Families. In study 2, additional ethical approval was granted by participating local authorities. Ethics considered research and participant welfare, referral process, confidentiality and consent and the ethical analysis and dissemination of the data.

\subsection{Study 1: A Regionally Coordinated Cross-Sector Response to Child Exploitation}

From January 2019, researchers from the Contextual Safeguarding team at the University of Bedfordshire were embedded within a regionally coordinated, cross-sector project, that aimed to understand and tackle the exploitation of children and young people from a particular form of EFH. The project was innovative, in that it brought together statutory and voluntary sector organizations, and analytic work with the provision of direct support. The project identified a cohort of young people impacted by this form of EFH across the region through the analysis of police data, and coordinated referrals from across the region to a central system. The project notified local areas about young people deemed to be 'at risk' and if there was no local provision for support, a referral was made for specialist case work from the commissioned voluntary and community sector organizations. The one-year study of this project utilized a range of research methods, including statutory and voluntary sector case file reviews ( $n=38)$, embedded observations of analysts and statutory multi-agency meetings $(n=18)$ and semi-structured interviews with statutory and voluntary sector workers $(n=39)$.

\section{Case Study 1: Identification, Mapping and Network Analysis}

The project aimed to coordinate responses to young people subject to EFH across the statutory and voluntary sector and policing, and to support the identification of young people 'at risk' through the use of police data and network mapping and analysis. The analysis of police data established a very large cohort of individuals involved in this form of EFH, six times larger than those who were referred to the project for support. The VCS organizations used a one-to-one case work model to work with young people on education, employment and training, awareness raising, and confidence building, as well as family work and advocacy around criminal justice interventions, and in response to school exclusions.

Individuals associated with child exploitation (as victims and perpetrators) were identified by project staff from police data (i.e., arrest reports) and from project referrals. The names, gender, ethnicity, address, 'gang' affiliation, locations frequented and police intelligence linking the individual to this form of EFH were recorded on a spreadsheet held by the project, and uploaded to police systems. The names of the young people on the spreadsheet up to the age of 25 were shared with local authority safeguarding leads and multi-agency safeguarding hubs. The full list of names (including young people and adults) from the police data and the project referrals were added to police systems. 
For those who were identified as in need of support (and where there was no local support provision available), the project referred the young person to the specially commissioned voluntary sector service for one-to-one case work.

Mapping work was carried out by the project team to support multi-agency risk panels, to identify young people and locations at risk. Information was gathered by the project analysts during multi-agency panels (such as names of young people and their friends) and then expanded using police data and the project referral data. The mapping depicted the names and ages of young people discussed in the panel, plus additional young people identified as associates or young people at risk, through police data and the project referral data (i.e., the names of siblings/family members or friends). The mapping established connections between young people and addresses/locations of harm or frequently occurring locations (e.g., schools) and 'gang' affiliation/association. The mapping also noted whether police data could evidence that the young person was subject to exploitation. This data was then shared with the regional police and a sanitized version without police data (other than that originally shared in the panel) was shared with the local authority via the multi-agency risk panel.

\subsection{Study 2: Developing and Embedding a Whole Systems Approach to Extra-Familial Harm}

From May 2017 to May 2019, researchers from the Contextual Safeguarding programme were embedded within one statutory child protection team in England to work with a project team (formed of social and youth work practitioners), to create and embed a Contextual Safeguarding approach to EFH. This action research study utilised a range of research methods, including observations of strategic and operational multi-agency meetings $(n=12)$, meeting participation $(n=16)$, reflective meetings $(n=7)$, weekly team and project meetings across two years, case file review $(n=43)$, practitioner interviews $(n=7)$, observations of practice and analysis of five context assessments, a school assessment $(n=1)$, neighbourhood assessments $(n=2)$ and peer group assessment $(n=3)$.

\section{Case Study 2: Context Assessments}

In study 2, the local authority piloted context assessments to engage with young people's experiences of EFH. Context assessments follow statutory child protection frameworks, but rather than assessing and intervening with individual children or families, do so with contexts. This work is developing nationally, and so far, has been trialled within schools, housing estates, restaurants, shopping centres and with peer groups. Here, a neighbourhood assessment was piloted in a small urban area, which encompassed a community centre, park, youth club, shops, and one primary school. The assessment was instigated following two incidents between January and March 2018 (the separate sexual and physical assault of young people). Further incidents and data prompted the authority to choose this location as the test site for a location assessment, including; data from an Integrated Gangs Unit (IGU) and recent crime data captured by the local authority data analyst. The assessment was led by two social workers, two youth work practitioners and a participation officer over 6 weeks, and involved a number of assessment activities, including:

- $\quad$ Forming a youth panel of 10 young people engaged weekly

- Five focus groups with young people from the youth club and school

- Young person engagement at the local youth club

- Business surveys with local businesses

- Review local regeneration board minutes

- A member of the assessment team located weekly in the community centre

- A weekend local community event to engage local residents and young people

The assessment concluded that the location "is a context in which young people may experience significant harm" (assessment report). The risks included "exposure to substance misuse, child and adult exploitation (sexual and criminal), harmful attitudes and violence, lack of resources and the normalization of these factors in this context" (assessment report). Following analysis, a context 
conference was convened, chaired by an independent reviewing officer and attended by ward councillors, the local youth service, substance misuse team, community safety, the IGU, community resilience partnership, anti-social behaviour team, housing and local businesses. No names or details were provided relating to individual young people or families, as it was the neighbourhood, not individuals, that were under assessment. At the context conference assessment, the findings were presented, and a plan was developed. The plan included a range of activities, including; alcohol and drugs outreach; community safety patrols; identification of community guardians and a single point of contact for local residents; training to businesses and options to indicate businesses as safe places for young people; detached youth work hired by local young people, and restorative interventions for young people that were identified during the neighbourhood assessment.

\section{Findings}

Both projects studied sought ways to respond to EFH. In doing so, they raise ethical questions about the rationale, methods and impact. Below, we critically analyse both studies using the framework developed in this article (Figure 1).

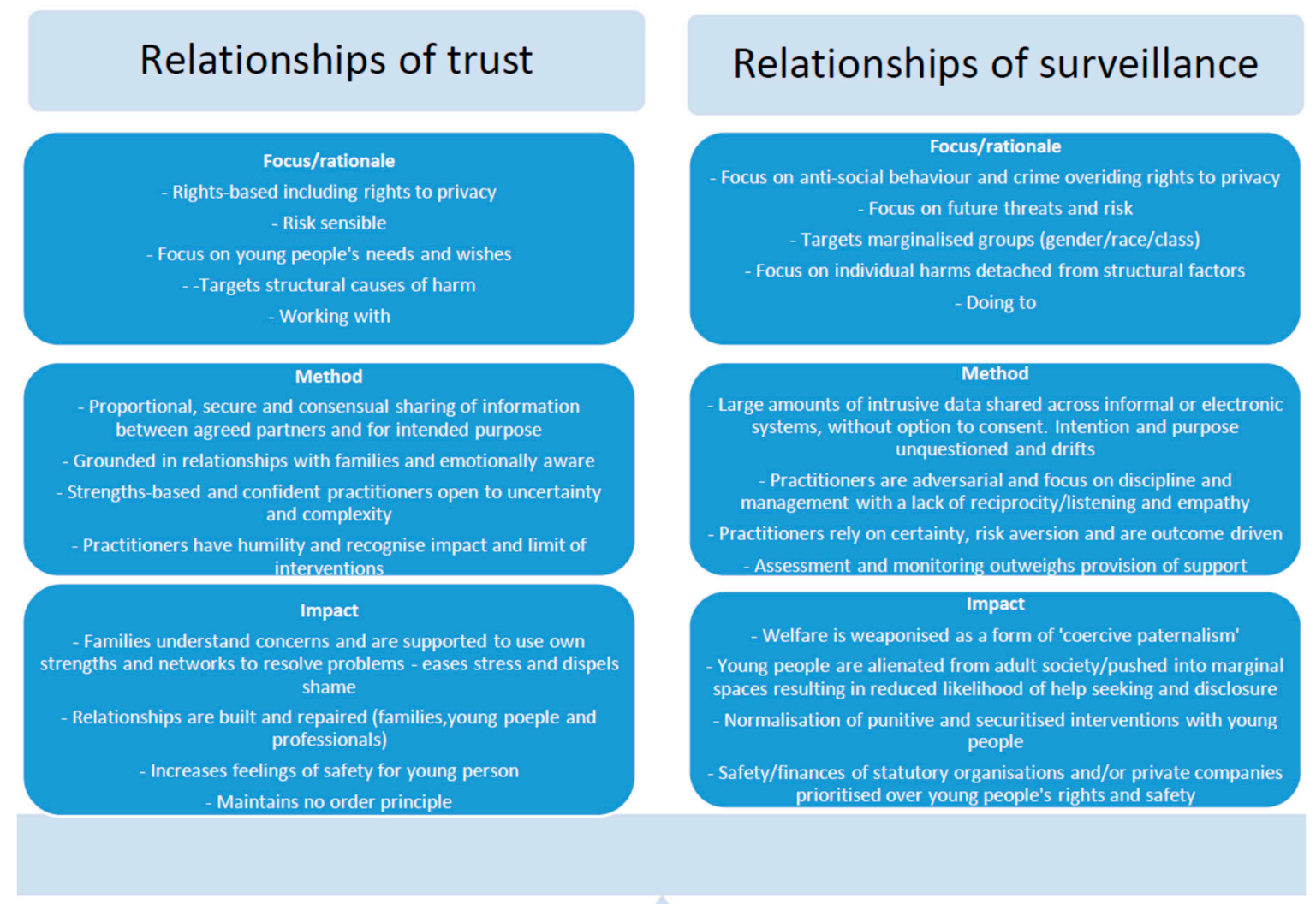

Figure 1. Relationships of trust or relationships of surveillance.

\subsection{Focus/Rationale}

Both projects sought, in different ways, opportunities to respond to young people's experiences of EFH through multi-agency working around a specific form or location of harm. Project 1 was motivated by a concern about the unknown reach and impact of a particular form of child exploitation 
in a geographical region of the UK. Whilst the focus was child safeguarding, the project was funded via policing and crime funds. The project aimed to combine intelligence gathering and sharing across the region, with the provision of specialist direct support for young people. It aimed to ensure young people most at risk, or on the cusp of exploitation, were known to services and a support service could be offered. An additional objective was ensuring those who perpetrate harm against young people could be brought to justice. The rationale for the project was that the issue of child exploitation, via this particular crime type, was little understood and that coordination was required at a regional level to tackle the issue. The project therefore had a dual rationale and focus: the prevention of crime and the safeguarding of children and young people. This is not unusual for multi-agency safeguarding partnerships where disruption and protection operate alongside each other, however, the at times competing and conflicting methods and impacts of these kinds of interventions require critical consideration (discussed below).

For project 2, the overwhelming rationale for the neighbourhood assessment was the recognition that young people had locally experienced physical and sexual harm, contributing to concerns that young people in the area were at risk of further harm. The project sought to conduct a neighbourhood assessment, develop a plan and intervene in the location. In some senses, the use of crime data and information from the IGU, contributed to the rationale underpinning the assessment-the reduction of future threats and risks, including the prevention of crime. However, by locating the assessment within children's social care, led by social workers and youth work practitioners, the team sought to root the assessment from a child welfare, as opposed to crime reduction, perspective.

Project 1 aimed to identify young people who were potential victims of exploitation. The project aims were then ostensibly aligned to the rights of children and young people to live lives free from abuse, to ensure their welfare is paramount and their best interests are protected. Despite this, an overwhelming majority of young people identified and documented through the project as at risk were identified through police data collected with a crime prevention priority. Police data are not an accurate reflection of crime or vulnerability, but in this instance were stored and shared across a range of agencies, using safeguarding and crime prevention legislation to override GDPR or data protection considerations, for example where information from referrals identifying young people at risk was shared with police partners and uploaded to police systems. The project was both motivated by present and future risk to young people. The collating and sharing of policing data that indicated involvement in this form of EFH (i.e., arrest data/stop and search reports) were legitimised by the project as allowing partners to identify young people not yet known to services (although many were) as 'at risk' of this particular form of child exploitation. The use of police data to identify young people at risk came with a number of inherent biases. Police data are only accurate representations of policing, not of crime, and it is well established that certain demographics of young people are policed at a higher rate than their peers (Lammy 2017). The project disproportionately collated and shared data in multi-agency settings about young people from Black, Asian and ethnic minority backgrounds and almost $60 \%$ of young people identified were already open to children's services.

In study 2 , the distinction between focusing predominantly on children's rights and welfare, as opposed to crime reduction, was more evident. Most strongly through the emphasis on working with members of the community within the location area, such as local residents, local businesses and schools and health services, and particularly through the early engagement of young people in order to focus on their needs and wishes (discussed below). Yet, in other ways, the trigger and focus for the assessment as 'working with' young people were less clear. As location assessments were not part of the everyday practice of this social care department, the referral route was atypical to how a child and family may enter the child protection system-via screening and threshold decisions based on level of harm (as opposed to crime) at the front door. As such, the authority determined the assessment location, based on data from a range of sources. Social workers in the team, and youth workers that sat on the project advisory board, were keen to choose a location based on reports from young people that they had experienced harm or felt unsafe in the area. However, the project's analyst and community 
safety partners promoted a location based predominantly on the combination of police crime data and information from social care referrals. Ultimately, the location was expanded to include a combination of both.

The issue of 'working with' or 'watching over' was complicated in project 1 . Whilst young people did not know, and therefore could not consent, to their information being collated and shared between policing and child welfare agencies, their consent was sought for a referral to one of the voluntary sector support services commissioned by the project. At this point young people's needs and wishes were taken into account and support services were responsive to these needs; supporting young people with education, employment and training, advocating around school exclusions, and ensuring National Referral Mechanism referrals were made and young people were supported in court. Although young people and families consented to take part in the intervention, the vast data gathering and sharing leading up to this point were conducted without their knowledge or consent.

Project 2 strongly promoted working with young people, but despite this, a number of challenges were raised. As in study 1, relying on police data provides only a partial representation of harm-which is likely to disproportionally target marginalized groups-or areas. Furthermore, the analyst and policing community safety colleagues were sceptical of relying on young people's 'anecdotal' experiences of safety. This can be seen to contribute to a hierarchy of experiences, where young people's experiences are subjugated, despite the fact low reporting rates mean that we already know very little about young people's experiences of crime (Beckett and Warrington 2015). In some respects, the focus on locations rather than individual children and family reduced the ability to intrude on individual rights to privacy, but in other ways the intervention could be seen to expand the role and remit of child protection, subjecting a greater number of young people (and the neighbourhood in which they live) to surveillance and monitoring, through a focus on places not people.

Both projects sought, in varying ways, to consider locational, if not structural, forms of harm. For example, project 2 aimed to address the impacts of ongoing regeneration and gentrification for young people from the area. Furthermore, interventions sought to question and raise the issues of gender and race, which underpinned some of their experiences of harm. For example, sessions with the youth group discussed the impact of policing and experiences of sexism. In study 1, caseworkers helped young people to navigate a range of structural factors that create the conditions for, and vulnerability to, child exploitation. For example, young people were supported to find means of earning money safely and legally, mediating poverty as a push factor into precarious and exploitative 'work'. However, these are individualized responses to structural factors; could efforts have been made to address structural harms to young people in the area, such as high levels of child poverty and school exclusions, both identified as drivers of this particular form of child exploitation?

\subsection{Methods}

The use of data in child welfare interventions featured heavily in the analytical framework. Both projects relied on a range of data sources to determine who and what was the focus and the rationale for the intervention. For project 1, the threshold for a young person being identified as at risk or on the cusp of exploitation was determined via two data sources: police crime data and referral data provided by multi-agency partners. The project shared this information between the project and its partners (including police and social care), without the consent of young people and families. Information was shared via usual multi-agency processes, such as verbally and in document form in multi-agency risk panels, through referrals to the Multi-agency Safeguarding Hub and directly to safeguarding teams and via mapping and network analysis documents to strategic panels. The information was shared securely and in sanitized form where required (i.e., removing policing data from information shared in non-police settings). The extent to which data were shared proportionally was tied to the proposed level of risk the young people were in/posed to others, and whether or not information sharing increased their safety. As the project data were shared across policing and child welfare spaces without consistent follow-up (as to how the data were used) it is 
difficult to establish if the information sharing was either proportionate or effective. In some cases, managers in the VCS organizations redacted referral information provided by the project, as it was felt that having too much information about a young person impacted on the ability to form trusted relationships and exacerbated existing power imbalances.

In project 2, information was not shared about individual children and families. Consent was an on-going process and raised a number of ethical questions. For elements where people were engaged directly, for example the youth participation groups, focus groups' and business surveys' consent was sought from individuals. Information from these sources was recorded by social workers and shared with other agencies anonymously. For other forms of data, for example that shared by the police and intelligence unit, existing information sharing and confidentiality agreements were used. While information relating to individuals was never shared, it was evident that some information was sourced from social media platforms and open source sites. While the focus was a location and not individuals, the project does, however, raise a number of questions about the scope and remit of assessments of this nature. Individuals, unless they were directly contacted, did not consent and were unaware of this process. Furthermore, practitioners within the project raised, on a number of occasions, issues around how the location assessment would be linked to children and families already known to their service. For example, how would plans developed for the area, or concerns raised, link to individual plans for children locally. Information was shared to the individual social workers of these families, but did not form part of the location assessment.

Practitioners in project 1 delivered support services in a relational way with young people and their families, drawing on empathy, lived experience and access to resources to form and maintain relationships with young people, that were flexible and patient in response to inconsistent attendance/engagement. The project recorded fairly rigid outcomes, such as a pre-specified number of young people it aimed to engage, and measures such as 'reduction in offending', which are not accurate indications of reduced vulnerability or increased safety. There were six times as many individuals deemed via police data to be involved in this form of child exploitation, whose data were collected, collated and shared, than those identified and referred to the project by agencies in the region. Of those referred to the projects support service $(7 \%$ of the total number of young people identified by the project), half were successfully engaged and just over half of those reported a reduction in involvement. The assessment and monitoring of the harm outweighed the provision of support.

Methods employed in study 2 varied significantly from study 1, most clearly, through the participation of young people and families within assessment. The project's assessment in study 2 was grounded in relationships with families. Throughout the project, one practitioner from the assessment team was located weekly in the local community centre within the assessment area. This allowed them to engage with local residents, businesses and services in the area and develop relationships forming the basis of the assessment, information captured and focus of interventions. Secondly, this same practitioner and the participatory lead formed, and met weekly, with a group of young people in the area. The information from these sessions guided the assessment and methods used, allowing practitioners to learn from the young people, to understand their experiences, develop strength-based interventions and be transparent about when and how information was used and shared.

\subsection{Impact}

Young people and families engaged through project 1 were supported in a relational and strengths-based way, and emotional and material support was provided to protect young people from criminalization and ensure their safety. However, the impact of the project went beyond the one-to-one case work delivered to young people, and although welfare was not used in a coercive manner by the case workers (i.e., young people's support was not contingent on their engagement or performance), the issue of child welfare provided the rationale for an extensive data collation and sharing exercise, that went beyond those young people who were at risk or deemed by child welfare agencies as being at risk of significant harm. Whilst locally, young people were engaged by caseworkers who could 
support them to participate in and gain access to support in their local communities, the broader remit of the project and the reported disproportionality raises questions about the impact of extensive data collecting and sharing on community/service relations, for those young people and families who already feel over-policed and over-intervened. The project promoted safeguarding responses to young people and the case work provided had a focus on welfare and de-criminalization, however the information collated and shared about young people, which detailed crime data and association with a particular crime type (sometimes as both perpetrator and victim), has unknown consequences for young people's futures. Finally, the engagement of a private company to work alongside the project to monitor patterns and trends on open source platforms again removed the assessment of risk and vulnerability away from young people and those that have trusted relationships with them.

The true extent of the impact of the assessment and subsequent intervention carried in project 2 is difficult to determine. In particular, it is hard to consider the extent that interventions can increase the safety of young people living locally. While this is certainly an aim, evidencing this proves difficult, for a number of reasons. Firstly, re-engaging those who were part of the first assessment would be challenging. Secondly, the catalyst for assessment was a number of sexual and physically violent incidents in the area, including the influence of criminal exploitation. Successful interventions for such harm are not clear-cut or easily available. Thirdly, the area was part of one of many locations undergoing significant amounts of regeneration. The assessment was used to inform elements of this, but it was clear it was not always the views and needs of families who shaped this agenda. Fourthly, while the assessment and interventions developed sought to work with families and children locally, such approaches run counter to other approaches locally-such as stop and search and cuts to essential services and welfare provision. It is within these wider contexts that the impact of interventions must be reviewed.

\section{Discussion and Conclusions}

The framework presented here provided a lens to examine emerging responses to EFH against long-standing debates in child and family social work, on the ethics of surveillance and relational approaches when working with families and communities. Core to the definition of three major forms of extra-familial harm (CSE, CCE and trafficking) are power, consent and exchange (Firmin et al. 2019). Often forms of EFH manipulate imbalances of power and the right to consent; grooming often masks exploitation as mutually beneficial. Service developments to EFH therefore need to repair, rather than replicate, the erosion of trust and consent that exploitation can instil in young people's early relational experiences (Warrington et al. 2017). This article proposes that there is a danger in advancing uncritically into the area of $\mathrm{EFH}$, without considering significant ethical and practice issues emerging from more traditional forms of child protection interventions. Application of the analytic framework to emerging responses to EFH highlights a number of crucial practice issues.

\subsection{Focus/Rationale}

Firstly, the focus and rationale of interventions must be transparent and reflexive. Collating and sharing information in multi-agency partnerships is not in itself benign and can have multiple unknown consequences for young people (as discussed above). This is particularly pertinent when we consider the complex ways EFH often manifests (i.e., through peer-to-peer 'recruitment', often involving 'offending' behaviour), and the environments where young people make decisions and act. This troubles dichotomous understandings of 'victim' and 'perpetrator'. Our analysis indicates that not only do interventions need to be clearly defined and transparent, but must actively, reflexively, and critically consider whether the safety of young people remains in focus and is protected in a context of competing service, and indeed political and economic, objectives.

Secondly, whilst the sharing of locational data moves away from individual level surveillance and intervention, it simultaneously opens possibilities for surveillance of broader populations of young people (and indeed anyone) using and moving through spaces. Location mapping can, then, impact 
civil liberties and be skewed with the same biases as person-level mapping. It should not be considered a loophole out of data protection and privacy considerations.

Finally, interventions to address EFH will inevitably encounter structures and systems that drive inter-personal harm and create vulnerable conditions for young people (i.e., poverty/lack of resources). Location-based or contextual approaches seek to move away from, or enhance, casework approaches, by targeting the conditions of abuse that create vulnerabilities for young people. The contexts of children's lives are broader than their friendship circles, schools and neighbourhoods, and location-based approaches could be further enhanced through the consideration of poverty-aware (Featherstone et al. 2018) or de-colonial (Harden et al. 2014) models of intervention. This not only ensures that interventions move beyond individualized responses to structural forms of harm, but also provides critical frameworks to monitor the extent to which interventions contribute to or exacerbate harmful and oppressive systems.

\subsection{Method}

Both projects raised questions about the boundaries and nature of information gathering and sharing, leading us to consider the question 'how much information is too much information?' Learning from project 1 centred a practical question: what information needs to be shared and why? There was also an ethical question: should we share information just because we can? Broadening the remit of safeguarding simultaneously broadens the occasions on which it is conceivable to share information in line with Working Together 2018 or the Crime and Disorder Act 1998, subjugating GDPR considerations. Just because the information is already available, or is publicly available, should it be used for this purpose and at this time? When do we need to seek, or re-seek consent? There is a danger that trust and relationships with young people become the collateral damage of loose and invasive information sharing arrangements.

How and when young people experiencing EFH are engaged requires further examination. It is well established that participation and trusted relationships are key to effective practice. Both projects raise questions about partnerships with young people. Do we consult young people during planning and implementation (as in project 2)? Or do we only engage young people at the point of service delivery (as in project 1)? In an era of advancing technology and automation, safeguarding partnerships increasingly rely on data-driven and algorithmic forms of problem detection (Carlo and Krueckeberg 2018). Arguably, such technologies can wedge a relational and spatial distance between young people, the problems they face and our understanding of them. Such approaches are burdened with bias, and simultaneously do not have the capacity to reflexively engage with that bias; an approach that we propose is critical for professionals engaging in interventions into EFH.

\subsection{Impact}

Interventions into EFH are only as good as their impact, which ultimately is the extent to which they create safety in young people's lives. Applying our analytical framework points us to a more nuanced understanding of 'impact'. Contextual approaches require a consideration of both contextual and individual outcomes, moving us away from individualized outcomes (as in project 2) that leave unsafe locations wide open to other young people. However, where do we draw the line at evaluating impact? If 20 young people are safer due to locational intervention requiring intrusive data collection and sharing without consent, what of the 150 other young people (and indeed adults) who were subject to monitoring without consent? Or for whom the profiling might have adverse future consequences? Is this a utilitarian question of greater good, or an indication that the impact has not been sufficiently examined and developed to consider the best interests of all? This raises our final question, can we evaluate impact without informing young people of the extent of intervention, asking them if they feel safer as a result? This is a question that some have begun to ask of more traditional forms of child protection intervention (Dillon et al. 2019) and should be central to the emerging scholarship and evaluation of approaches to EFH. 
We propose a framework for evaluating interventions into EFH and suggest that its application guides the sector, as it navigates new forms of harm and a responsibility to respond. If the objective of interventions is creating safety in young people's lives, we must be transparent in the focus and rationale of interventions, consider whether the methods we adopt promote relationships of trust, or relationships of control, and establish the impact of our work, by including the feedback of young people, whilst looking beyond individual outcomes to establish the broader ethical and societal impact of child protection interventions.

We welcome the enthusiastic uptake of Contextual Safeguarding practices nationally. Contextual Safeguarding is shaped through collaboration with practitioners and in this sense is not prescriptive. We are seeing the practice develop in new and exciting ways. Yet, alongside innovation, we are also faced with practice developments that, while not aligning to the principles of Contextual Safeguarding, are presented under its banner. It is not possible to be attuned to all of these practices. In presenting this article, we caution against Contextual Safeguarding becoming the next 'Trojan horse' of child protection, facilitating the expansion and intrusion of surveillance into the lives of children and families. In presenting the analytical framework, we seek to provide practitioners, and indeed researchers, with a tool to critically reflect on interventions into EFH.

Author Contributions: Conceptualization, L.E.W. and J.L.; methodology, L.E.W. and J.L.; formal analysis, L.E.W. and J.L.; writing-original draft preparation, L.E.W. and J.L.; writing-review and editing, L.E.W. and J.L.; visualization, L.E.W. and J.L.; funding acquisition, Contextual Safeguarding team. All authors have read and agreed to the published version of the manuscript.

Funding: This projects under investigation in this research were funded by a range of sources which are withheld here for project anonymity.

Acknowledgments: The authors would like to thank all individuals and agencies that have facilitated our embedded research.

Conflicts of Interest: The authors declare no conflict of interest. The funders of the projects under investigation had no role in the design of the study; in the collection, analyses, or interpretation of data; in the writing of the manuscript, or in the decision to publish the results.

\section{References}

ADCS. 2017. ADCS Response to Working Together to Safeguard Children: Changes to Statutory Guidance. Available online: https://adcs.org.uk/assets/documentation/ADCS_response_Working_Together_FINAL_20_ December_2017.pdf (accessed on 17 September 2019).

ALDCS. 2018. The Response of London Children's Services to Serious Youth Violence and Knife Crime-May 2018. Available online: https://www.londoncouncils.gov.uk/node/34040 (accessed on 6 January 2019).

Amnesty. 2018. Trapped in the Gangs Matrix. Available online: https://yjlc.uk/child-spies-being-used-to-gatherintelligence/ (accessed on 24 February 2020).

Beckett, Helen, and Camille Warrington. 2015. Making Justice Work: Experiences of Criminal Justice for Children and Young People Affected by Sexual Exploitation as Victims and Witnesses. Luton: University of Bedfordshire.

Bryan, Agnes, Helen Hingley-Jones, and Gillian Ruch. 2016. Relationship Based Practice Revisited. Journal of Social Work Practice 30: 229-33. [CrossRef]

Care Crisis Review. 2018. Care Crisis Review: Options for Change. London: Family Rights Group.

Carlo, Silkie, and Jennifer Krueckeberg. 2018. The State of Surveillance in 2018. Available online: https: //bigbrotherwatch.org.uk/wp-content/uploads/2018/09/The-State-of-Surveillance-in-2018.pdf (accessed on 27 February 2020).

Community Practitioner. 2019. Knife Crime: Where's the Public Health Approach? Available online: https://www.communitypractitioner.co.uk/sites/default/files/media/document/2019/news_big_ story_community_practitioner_julyaugust_2019_community_practitioner_magazine.pdf (accessed on 24 February 2020).

Cossar, Jeanette, Marian Brandon, and Peter Jordan. 2016. 'You've got to trust her and she's got to trust you': Children's views on participation in the child protection system. Child \& Family Social Work 21: 103-12. 
Department for Education. 2018a. Keeping Children Safe in Education Staturotry Guidance for Schools and Colleges. London: Crown Copyright.

Department for Education. 2018b. Working Together to Safeguard Children. London: Author.

Department for Education. 2019. Characteristics of Children in Need: 2018 to 2019. Available online: https://assets.publishing.service.gov.uk/government/uploads/system/uploads/attachment_data/file/ 843046/Characteristics_of_children_in_need_2018_to_2019_main_text.pdf (accessed on 25 February 2020).

Dillon, Jo, Daz Greenop, and Mel Hills. 2019. Participation in Child Protection; A small-scale qualitative study. Qualitative Social Work 15: 70-85. [CrossRef]

Edwards, Frank. 2016. Saving Children, Controlling Families: Punishment, Redistribution, and Child Protection. American Sociological Review 81: 575-95. [CrossRef]

Eubanks, Virginia. 2018. Automating Inequality: How High Tech Tools Profile, Police and Punish the Poor. New York: St Martins Press.

Featherstone, Brid, Anna Gupta, Kate Morris, and Sue White. 2018. Protecting Children: A Social Model. Bristol: Policy Press.

Fernandez, Luis A., and Laura Huey. 2009. Is resistance futile? Some thoughts on resisting surveillance. Surveillance E Society 6: 198-202.

Fine, Michelle, Nick Freudenberg, Yasser Payne, Tiffany Perkins, Kersha Smith, and Katya Wanzer. 2003. "Anything can happen with police around": Urban youth evaluate strategies of surveillance in public places. Journal of Social Issues 59: 141-58. [CrossRef]

Firmin, Carlene. 2017. Abuse between Young People: A Contextual Account. Oxon: Routledge.

Firmin, Carlene, Lauren Wroe, and Jenny Lloyd. 2019. Safeguarding and Exploitation-Complex, Contextual and Holistic Approaches. Strategic Briefing. Darlington: Research in Practice.

Harden, Troy, Thomas Kenemore, Kimberley Mann, Michael Edwards, Christine List, and Karen Jean Martinson. 2014. The truth ' $n$ ' trauma project: Addressing community violence through a youth-led, trauma-informed and restorative framework. Child and Adolescent Social Work Journal 32: 65-70. [CrossRef]

Hingley-Jones, Helen, and Gillian Ruch. 2016. 'Stumbling through'? Relationships-based social work practice in austere times. Journal of Social Work Practice 30: 235-48. [CrossRef]

Jay, Alexis. 2014. Independent Inquiry into Child Sexual Exploitation in Rotherham: 1997-2013; Rotherham: Rotherham Metropolitan Borough Council.

Lammy, David. 2017. The Lammy Review: An Independent Review into the Treatment of, and Outcomes for, Black, Asian and Minority Ethnic Individuals in the Criminal Justice System. Available online: https://assets.publishing.service.gov.uk/government/uploads/system/uploads/attachment_data/file/ 643001/lammy-review-final-report.pdf (accessed on 24 February 2020).

Lloyd, Jenny, and Carlene Firmin. 2019. No Further Action: Contextualising Social Care Decisions for Children Victimised in Extra-Familial Settings. Youth Justice. ahead-of-print. [CrossRef]

Llywodraeth Cymru. 2019. Safeguarding children from Child Sexual Exploitation (CSE). Available online: https://gov.wales/safeguarding-children-child-sexual-exploitation (accessed on 24 February 2020).

McKendrick, David, and Jo Finch. 2017. ‘Under heavy manners?': Social work, radicalisation, troubled families and non-linear war. British Journal of Social Work 47: 308-24. [CrossRef]

Mellon, Maggie. 2017. Child Protection: Listening and Learning from Parents. Available online: https://www.iriss. org.uk/resources/insights/child-protection-listening-and-learning-parents (accessed on 24 February 2020).

Montgomery, Kathryn C. 2015. Youth and surveillance in the Facebook era: Policy interventions and social implications. Telecommunications Policy 39: 771-86. [CrossRef]

Morris, Kate. 2012. Troubled families: Vulnerable families experiences of multiple service use. Child and Family Social Work 18: 198-206. [CrossRef]

Munro, Eileen. 2011. The Munro Review of Child Protection: Final Report, a Child-Centred System. London: The Stationery Office, vol. 8062.

O'Neill, Megan, and Bethan Loftus. 2013. Policing and the surveillance of the marginal: Everyday contexts of social control. Theoretical Criminology 17: 437-54. [CrossRef]

Parton, Nigel. 2000. Some thoughts on the relationship between theory \& practice in and for social work. British Journal of Social Work 30: 449-63.

Parton, Nigel. 2011. Child protection and safeguarding in England: Changing and competing notions of risk and their implications for social work. British Journal of Social Work 41: 845-75. [CrossRef] 
Parton, Nigel. 2019. Changing and competing conceptions of risk and their implications for public health approaches to child protection. In Re-Visioning Public Health Approaches for Protecting Children. Edited by Bob Lonne, Deb Scott, Daryl Higgins and Todd Herrenkohl. Basel: Springer, chp. 5, pp. 65-78. ISBN 978-83-030-05857-9.

Penna, Sue. 2005. The Children Act 2004: Child Protection and Social Surveillance. Journal of Social Welfare and Family Law 27: 143-57. [CrossRef]

Shabde, Neela, and Alan W. Craft. 1999. Covert video surveillance: An important investigative tool or a breach of trust? Archives of Disease in Childhood 81: 291-94. [CrossRef]

Shade, Leslie Regan, and Rianka Singh. 2016. "Honestly we're not spying on kids": School surveillance of young people's social media. Social Media and Society 2: 1-12. [CrossRef]

Stability Index. 2019. Available online: https://childrenscommissioner.github.io/stabilityindex2019/ (accessed on 27 February 2020).

Stanley, Tony, Surinder Guru, and Anna Gupta. 2018. Working with PREVENT: Social work options for cases of 'radicalisation risk'. Practice: Social Work in Action 30: 131-46. [CrossRef]

Twite, Jennifer. 2018. Child Spies Being Used to Gather Intelligence on County Lines Gangs. Available online: https://yjlc.uk/child-spies-being-used-to-gather-intelligence/ (accessed on 24 February 2020).

United Nations Convention on the Rights of the Child. 1989. United Nations, Treaty Series; New York: United Nations, vol. 1577, p. 3.

van Bijleveld, Ganna G., Christine W. M. Dedding, and Joske F. G. Bunders-Aelen. 2013. Children's and young people's participation within child welfare and child protection services: A state-of-the-art review. Child and Family Social Work 20: 129-38. [CrossRef]

Warrington, Camille, Elizabeth Ackerley, Helen Beckett, Megan Walker, and Debbie Allnock. 2017. Making Noise: Children's Voices for Positive Change after Sexual Abuse. Luton: University of Bedfordshire/Office of Children's Commissioner.

White, Sue, and David Wastell. 2017. The rise and rise of prevention science in UK family welfare: Surveillance gets under the skin. Families, Relationships and Societies 6: 427-45. [CrossRef]

Williams, Patrick. 2018. Being Matrixed: The (Over)Policing of Gang Suspects in London. London: StopWatch, Available online: www.stop-watch.org/uploads/documents/Being_Matrixed.pdf (accessed on 28 February 2020).

Williams, Patrick, and Becky Clarke. 2016. Dangerous Associations: Joint Enterprise, Gangs and Racism: An Analysis of the Processes of Criminalisation of Black, Asian and Minority Ethnic Individuals. Centre for Crime and Justice Studies. Available online: https://www.crimeandjustice.org.uk/sites/crimeandjustice.org. uk/files/Dangerous\%20assocations\%20Joint\%20Enterprise\%20gangs\%20and\%20racism.pdf (accessed on 24 February 2020).

Wrennall, Lynne. 2010. Surveillance and child protection: De-mystifying the Trojan Horse. Surveillance E Society 7: 304-24.

(C) 2020 by the authors. Licensee MDPI, Basel, Switzerland. This article is an open access article distributed under the terms and conditions of the Creative Commons Attribution (CC BY) license (http://creativecommons.org/licenses/by/4.0/). 